\title{
MULTIPLE APPROACHES OF SOLVING ALLOCATION PROBLEMS ON POSTAL TRANSPORTATION NETWORK IN CONDITIONS OF LARGE COUNTRIES
}

\author{
Radovan Madleňák ${ }^{1}$, Lucia Madleňáková ${ }^{2}$, Jozef Štefunko ${ }^{3}$, Reiner Keil ${ }^{4}$ \\ ${ }^{1}$ University of Zilina, Zilina, Slovakia \\ $++421 / 41 / 5133124$,radovan.madlenak@fpedas.uniza.sk \\ ${ }^{2}$ University of Zilina, Zilina, Slovakia \\ ++421/41/5133125, lucia.madlenakova@fpedas.uniza.sk \\ ${ }^{3}$ University of Zilina, Zilina, Slovakia \\ $++421 / 41 / 5133145$,jozef.stefunko@fpedas.uniza.sk \\ ${ }^{4}$ Technische Universität Dresden, Dresden, Germany \\ ++49/351/46336795, reiner.keil@tu-dresden.de
}

\begin{abstract}
The article deals with the optimizing the postal transportation network with two different optimizing methods. The research adopted in this article uses allocation models within graph theory to obtain results for addressed optimization problem. The article presents and compares two types of these models: p-median and uncapacitated fixed charge facility location model. The aim of pmedian model is to find the location of $\mathrm{P}$ facilities in network, serving all demands in a way ensuring the average transport cost to be minimal. Fixed charge location model approach the issue of facility location based on minimizing the overall costs of implementation of selected variants. The latter this two models are subsequently applied on the postal network to determine the optimal location of postal facilities. These two models are adopted in the condition of large country with area above $300000 \mathrm{~km}^{2}$. The Italy was chosen as a typical country that fits this condition. The underlying infrastructure of Italy is represented by simplified model of a postal network, abstracted by a graph $\mathrm{G}=(\mathrm{V}, \mathrm{E}, \mathrm{c}, \mathrm{w})$.

The results can serve as a basis for modification of the used models for the simulation of networks in the postal sector and as a key that compares the opportunities and results of application of these two models in the conditions large countries.
\end{abstract}

Keywords: optimization, postal networks, location problems, p-median, uncapacitated fixed charge location model

\section{Introduction}

Decision of facilities location is an integral part of public and private sector. For example, state government needs to determine locations for bases for emergency highway patrol vehicles. Similarly, local governments must locate fire stations and ambulances. In all three of these cases, poor locations can increase the likelihood of property damage and/or loss of life. In private sector, industry must locate offices, production and assembly plants, distribution centers, and retail outlets. Poor location decisions in this environment lead to increased costs and decreased competitiveness. This issue is addressed in socalled allocation problems (Ahuja et al., 1993).

There are several methods for modeling and solving allocation problems. The most important are methods of integer linear programing and graph theory. Allocation problems differ in type of objective function and model of the environment in which they are addressed (Daskin, 2010). Model of environment, in our case, is the transportation network abstracted by the complete weighted graph $G=(V, E, c, w) . V$ is the set of vertices representing possible facility locations. $E$ is the set of edges representing connections between nodes (vertices). Label $c(e)$ of edge $e \in E$ is its length. Weight $w(v)$ of node $v \in V$ represents the importance of node in addressed system (number of demands, etc.) (Hakimi, 1964).

Some nodes can serve as centers. These centers can generally have two functions - rescue or supply. When speaking about rescue function, the center is called the emergency center. These apply for ambulance locations, etc. The significant criterion in this case is the reachability of the worst located (furthest) node of a graph. The task is to find the optimal location of emergency centers so the demand of the worst located node would be served on time (Čorejová et al., 1995).

The supply function of center is characterized by term depot. The depot is for example the warehouse of material. Each node of a graph $G=(V, E, c, w)$ need $w(v)$ material units per time unit, while the unit costs for supplying the material are proportional to the travel distance. In this case, the location of 
centers is performed in such way, that the total transport costs of serving all nodes are minimized (Droździel et al., 2008). Postal processing and distribution centers thus perform the supply function.

\section{Analysis of allocation models}

To find the optimal (or sup-optimal) location of depots in postal network it is suitable to use discrete network allocation models. One of the basic parameters for solving such problems is the very distance between nodes. From this point of view, it is possible to subdivide allocation models into two categories (Madleňák et al., 2015):

- Models based on maximum distance (set covering, maximum covering, p-center).

- Models based on total/average distance (p-median, maxisum, fixed charge location model).

For networks with supplying function it seems as the most appropriate to use the models based on total or average distance. These models are based on the average distance between depots and all demand nodes, ensuring that this average distance will be as minimal as possible (as well as the sum of travel distances to cover the whole network) (Daskin, 2013). Further in this article we will deal with p-median and uncapacitated fixed charge location model.

\subsection{P-median model}

The p-median problem is one of the basic questions of location theory and is as follows: The spatial distribution and the amount of demand for a certain service or facility are known. The task is to find locations for a given number of facilities that satisfy the demand. The facility locations are optimal, if the weighted travel efforts from the demand points to the nearest facilities are minimized. The problem is uncapacitated, which means that a facility can match any amount of demand necessary (Hakimi, 1964).

This model works with following set of variables (Tab. 1):

Table 1. Variables used in p-median location model (Daskin, 2013)

\begin{tabular}{|c|c|c|c|c|}
\hline \multicolumn{2}{|r|}{ Input variables } & \multicolumn{3}{|r|}{ Decision variables } \\
\hline Notation & Description & Notation & & Description \\
\hline$I$ & set of nodes with demands to be served & \multirow[b]{2}{*}{$X_{j}$} & \multirow{2}{*}{\multicolumn{2}{|c|}{$\begin{array}{ll}=1 & \begin{array}{l}\text { if we locate facility at candidate } \\
\text { node } j\end{array} \\
=0 & \text { if not }\end{array}$}} \\
\hline$J$ & set of candidate nodes for facility location & & & \\
\hline$h_{i}$ & demand at node $i$ & \multirow{3}{*}{$Y_{i j}$} & & \multirow{3}{*}{$\begin{array}{l}\text { if demands at node } i \text { are served by } \\
\text { facility at node } j \\
\text { if not }\end{array}$} \\
\hline$d_{i j}$ & $\begin{array}{l}\text { distance between demand node } i \text { and candidate } \\
\text { node } j\end{array}$ & & & \\
\hline$P$ & number of facilities to locate & & & \\
\hline
\end{tabular}

The p-median location problem can be formulated as follows:

$\sum_{i} \sum_{j} h_{i} d_{i j} Y_{i j}$

$\sum_{j} Y_{i j}=1 \quad \forall i \in I$,

$\sum_{j} X_{j}=P$

$Y_{i j} \leq X_{j} \quad \forall i \in I, j \in J$

$X_{j}, Y_{i j} \in\{0,1\} \quad \forall i \in I, j \in J$.

The optimizing function (1) minimizes the total demand weighted distance between individual nodes and closest centres. Constraint (2) requires each node $i$ to be assigned to exactly one facility at node $j$. Constraint (3) ensures that exactly $P$ facilities will be located. Constraint (4) states that demands at node $i$ can only be assigned to a facility at location $j$ if a facility is located at node $j$. Constraints (5) are standard integrality conditions (Daskin, 2013). 


\subsection{Uncapacitated fixed charge model}

Uncapacitated fixed charge facility location (UFCFL) model approach the issue of facility location based on minimizing the overall fixed costs and transport costs. This model works with following assumptions (Cornuejols et al., 1990):

- Locating facility in candidate nodes might not imply the same fixed cost in each of them;

- Number of facilities to be located is not input of the model;

- The theoretical capacity of facility is unlimited, thus the demands are assigned based on shortest distance.

The solution of this problem will be the optimal number and position of facilities in a graph while minimizing the total costs of the model. The assumed unlimited theoretical capacity of located facilities will ensure that all demands are served (Fig. 1).

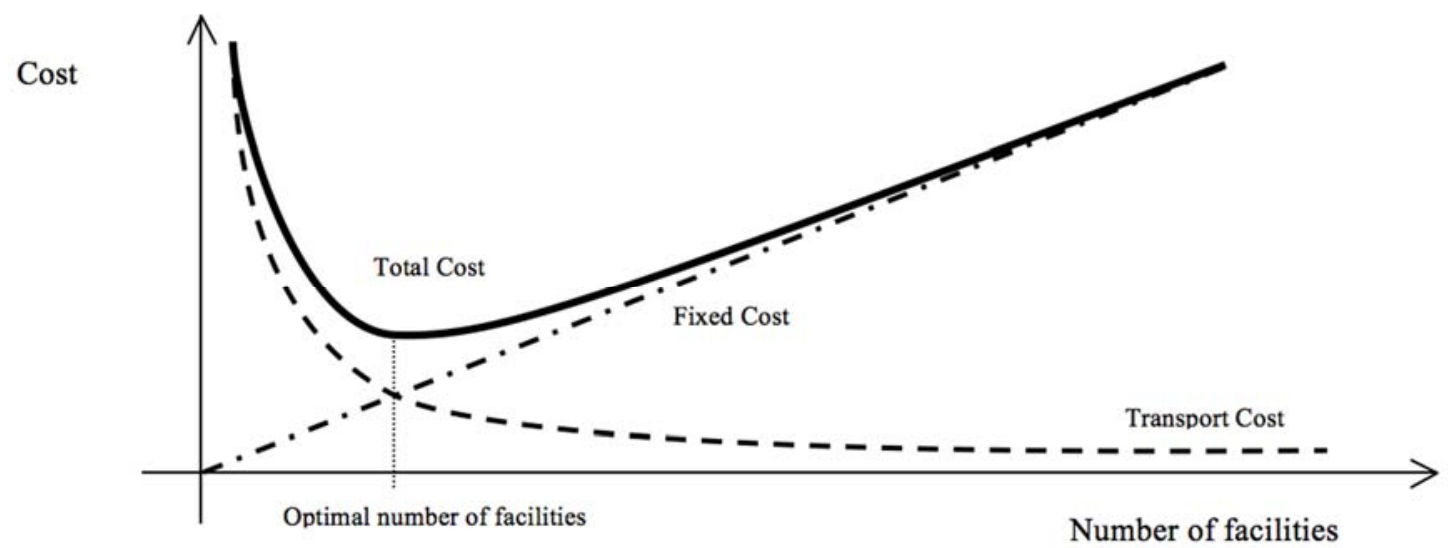

Figure 1. Principle of uncapacitated fixed charge location models (Cornuejols et al., 1990)

This model works with following set of variables (Tab. 2):

Table 2. Variables used in uncapacitated fixed charge facility location model (Daskin, 2013)

\begin{tabular}{|c|c|c|c|}
\hline \multicolumn{2}{|r|}{ Input variables } & \multicolumn{2}{|r|}{ Decision variables } \\
\hline Notation & Description & Notation & Description \\
\hline$I$ & set of nodes with demands to be served & \multirow{3}{*}{$X_{j}$} & \multirow{3}{*}{$\begin{array}{l}=1 \\
=0\end{array}$} \\
\hline$J$ & set of candidate nodes for facility location & & \\
\hline$h_{i}$ & demand at node $i$ & & \\
\hline$d_{i j}$ & $\begin{array}{l}\text { distance between demand node } i \text { and candidate } \\
\text { node } j\end{array}$ & \multirow{3}{*}{$Y_{i j}$} & \multirow{3}{*}{$\begin{array}{l}\text { fraction of demands at node } i \text { that is served by a } \\
\text { facility at node } j\end{array}$} \\
\hline$f_{j}$ & fixed costs of locating candidate node $j$ & & \\
\hline$\alpha$ & costs per distance unit per demand unit & & \\
\hline
\end{tabular}

The optimization problem can be formulated as follows:

$\sum_{j} f_{j} X_{j}+\alpha \sum_{i} \sum_{j} h_{i} d_{i j} Y_{i j}$,

$\sum_{j} Y_{i j}=1 \quad \forall i \in I$,

$Y_{i j} \leq X_{j} \quad \forall i \in I ; \forall j \in J$,

$X_{j} \in\{0,1\} \quad Y_{i j} \geq 0 \quad \forall i \in I, j \in J$.

The optimizing function (6) minimizes the total costs, which is the sum of the fixed facility costs and transport costs (total demand weighted distance multiplied by costs pre distance unit per demand unit). Constraint (7) requires each node $i$ to be served. Constraint (8) ensures that demands at node $i$ 
cannot be assigned to a facility at candidate node $j$ unless we locate the facility at node $j$. Constraints (9) are the integrality and non-negativity conditions (Daskin, 2013).

\subsection{Algorithms for solving selected allocation problems}

Formulating an appropriate model is only one step in analyzing location problem. More challenging is to find the suitable algorithm to identify the optimal solution. The first approach is to apply well-known algorithms such as branch and bound. This work on most instances of location models, but is it limited on small scale problems. Realistically scaled location models can have thousands of computations, which consume unacceptable computational memory and time (Garey and Johnson, 1979).

To avoid this situation, or shorten the consumption of computational resources, other methods were defined to identify at least the "very good" solution. These methods are known as heuristic, and will not guarantee finding the optimal solution or identifying the difference from optimal solution. Therefore, such solution is referred as sub-optimal (Dresner and Hamacher, 2002). Heuristic algorithms for solving mentioned location problems can be divided into two main groups (Madleňák, 2006):

\section{Construction algorithms}

Such algorithms apply greedy heuristic to obtain the subset of facilities from the initial set. It works on a sequential approach that begins by evaluating each location individually and selecting the one that has the greatest impact on objective. The facility on that location is then fixed. Next facility is located in similar manner by calculation of remaining possible locations and identifying the best improvement in objective. Such approach for solving p-median location problem is known as myopic algorithm.

The greedy heuristic for minimizing objective function of total costs when solving uncapacitated fixed charge location problem can be applied in two ways. The approach when the initial set of facilities is empty and facilities are added to optimize the solution is known as ADD algorithm.

The DROP algorithm proceeds in reverse manner. The initial solution consists of facilities in every node and continues with removal of facility that minimizes the objective function the most. The removed facility is then excluded until the end of algorithm. Both algorithms stop when subsequent solution is worse than the previous one. This approach provides feasible solution with modest computational effort. However, the results can be usually improved.

\section{Improvement algorithms}

Such algorithms have been developed to improve the solution of construction algorithms. The well-known approach is neighborhood heuristic (Maranzana, 1964). The initial solution is divided to neighborhoods which are the sets of nodes that have demands assigned to each facility. Each potential facility relocation within each neighborhood is then calculated and performed based on best improvement. After facilities relocation, new neighborhoods are defined (if applicable) and the algorithm is repeated until no further changes improve the solution.

The other improvement method was introduced by Teitz and Bart (1968). The initial set of facilities locations is considered for relocation into unused locations. For each facility from initial set the best replacement node is identified. The pair with the best improvement of overall objective is then selected for relocation. When the improved solution is obtained and applied, demands are reassigned according to shortest weighted distance. The search process is repeated until no further improvement can be find. Such approach is known as exchange or substitution algorithm. Depending on the nature of initial solution the potential impact of entire facility removal can be calculated prior each substitution as well.

\section{Underlying infrastructure}

We are optimizing the existing postal network in the Italy. There is a multi-level structural variant of postal network implemented. The lowest level consists of regular post offices. The postal items are then forwarded through some middle-level nodes to high-level nodes. The process works similarly in the opposite direction - from higher to lower level nodes (Madleňák, 2006). This process ensures the covering of the whole territory of Italy.

The underlying infrastructure is represented by simplified model of a postal network, abstracted into a graph $G=(V, E, c, w)$. The set of vertices (nodes) $V$ consists of all 110 existing middle-level nodes that are designed to regional centers of Italy. The set of edges $E$ represents road and airplanes connections between nodes. Due to the strategic character and long-term impact of solution, we are taking into account completely built up network of planned highways and motorways while searching for road 
connection. Planes connect nodes between islands and main north and south cities. The labels of edges $c(e)$ have value of the shortest distance that specified by time (in minutes) spent on the road (or airplane). When determining the weight of nodes $w(v)$, we use the demographic characteristics of individual nodes and the covering region which they serve. As weight of the nodes we use number of citizens in the middle-level region. The map of covering regions of addressed network is presented below (Fig. 2) (Madleňák et al., 2014).

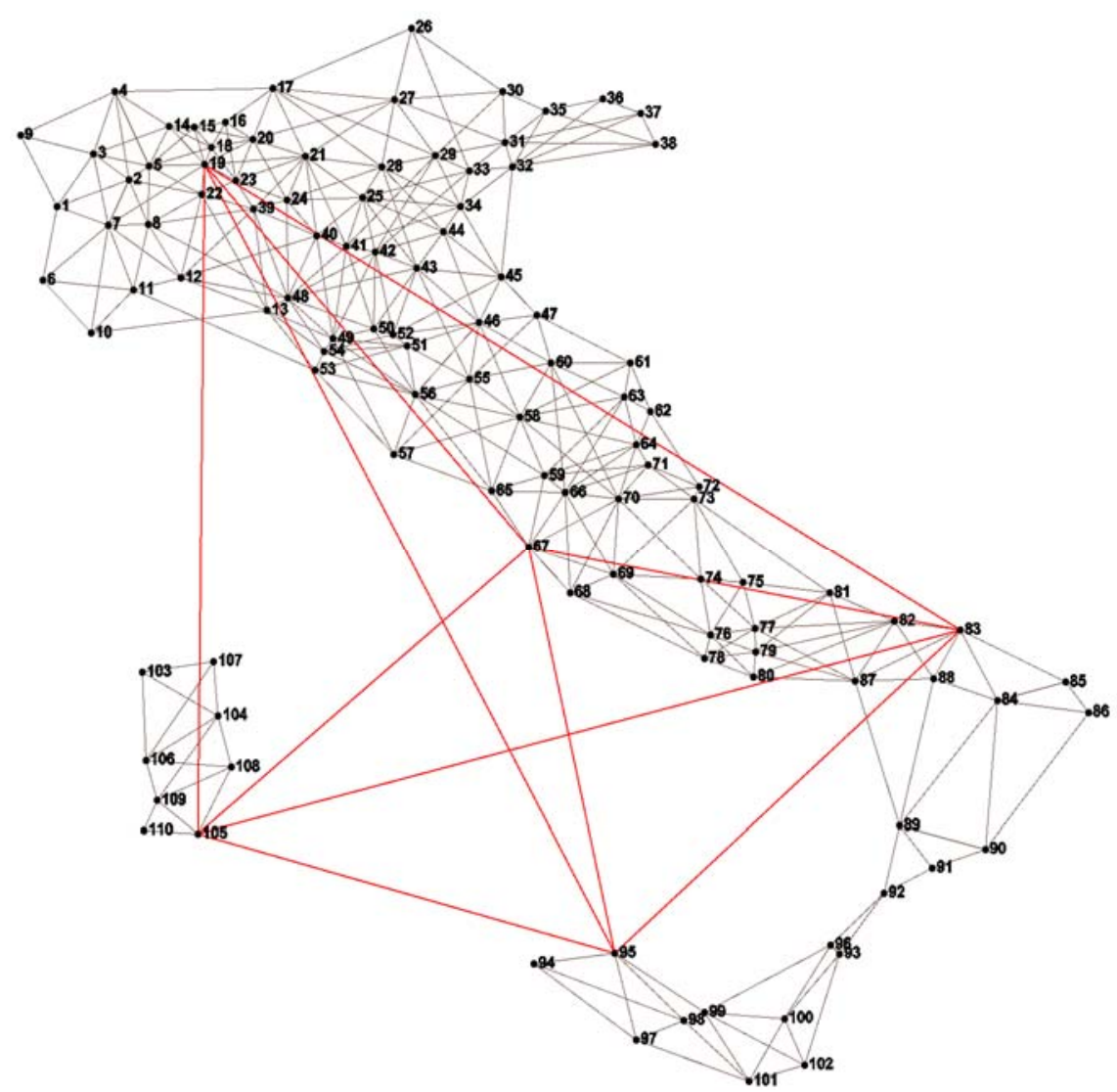

Figure 2. Underlying infrastructure of Italy

The covering distance (time) was set to 240 minutes. The uncapacitated fixed charge location model uses another two characteristic variables, which are necessary to be set prior to obtaining the final solution (Madleňáková, 2014). One of those are fixed costs for the location and build of facility at certain node. We consider the standardized model of postal sorting center, which would have the same construction for all locations. The basic value is set to $1000000 \mathrm{EUR}$, which resulted from similar projects implemented in practice in recent past. In addition, it is necessary to take into account the specifics of regions.

Another required input variable is the cost coefficient per distance unit per demand unit. It is necessary to determine the weight of demand and transport costs. When calculating the demand weight, we used the available statistical data (UPU, 2015). The final value of required coefficient is 0.004873 EUR per distance unit per demand unit. This value was computed on the average annual amount of mail per capita, transport costs per kilometer consist of fuel and oil consumption, vehicle wear and tear or depreciation and in addition we have to calculate with rent, driver salary, etc. Since the edges of network are evaluated in time units, required coefficient has been recalculated to minutes based on average time computed for whole network. Thus the value represents costs per minute per demand unit (Madleňák and Zeman, 2009).

\section{Results}

The task of the models is to find the number and location of high-level nodes in the network (Hrudkay, 2012). For p-median model we have to find minimal number of centers that covers demands of all nodes within required covering distance. And for uncapacitated fixed charge model we are trying to 
minimize the costs of building the facilities and serving the demands of network. The solutions can be achieved by using presented heuristic algorithms. Obtained solutions are presented below.

Table 3. Obtained solution for p-median model

\begin{tabular}{|c|c|c|}
\hline \multicolumn{2}{|l|}{ Number of centers } & 11 \\
\hline \multicolumn{2}{|c|}{ Location of the center (number of node) } & $\begin{array}{r}\text { Torino (1) } \\
\text { Milan (19) } \\
\text { Padova (33) } \\
\text { Bologna (43) } \\
\text { Firenze (51) } \\
\text { Roma (67) } \\
\text { Napoli (78) } \\
\text { Bari (83) } \\
\text { Palermo (95) } \\
\text { Messina (96) }\end{array}$ \\
\hline \multicolumn{2}{|l|}{ Total covered demands } & 59433744.00 \\
\hline \multicolumn{2}{|l|}{ Percent of covered demands [\%] } & 100.00 \\
\hline \multirow{3}{*}{ Average weighted distance [min.] } & All nodes & 60.01 \\
\hline & Covered nodes & 60.01 \\
\hline & Uncovered nodes & 0.00 \\
\hline \multicolumn{2}{|l|}{ Maximum distance [min.] } & 234.00 \\
\hline
\end{tabular}

By application of p-median location model we found out that the minimum number of facilities (centers) for given input values are achieved when locating eleven facilities at nodes representing the covering regions of cities Torino, Milano, Padova, Bologna, Florence, Roma, Naples, Bari, Palermo, Messina and Medio Campidano. The establishment of this set of high-level nodes in these locations ensures that the all demands/requirements of the nodes of the entire Italian territory will be satisfied. The final solution for p-median model is presented below (Fig. 3).
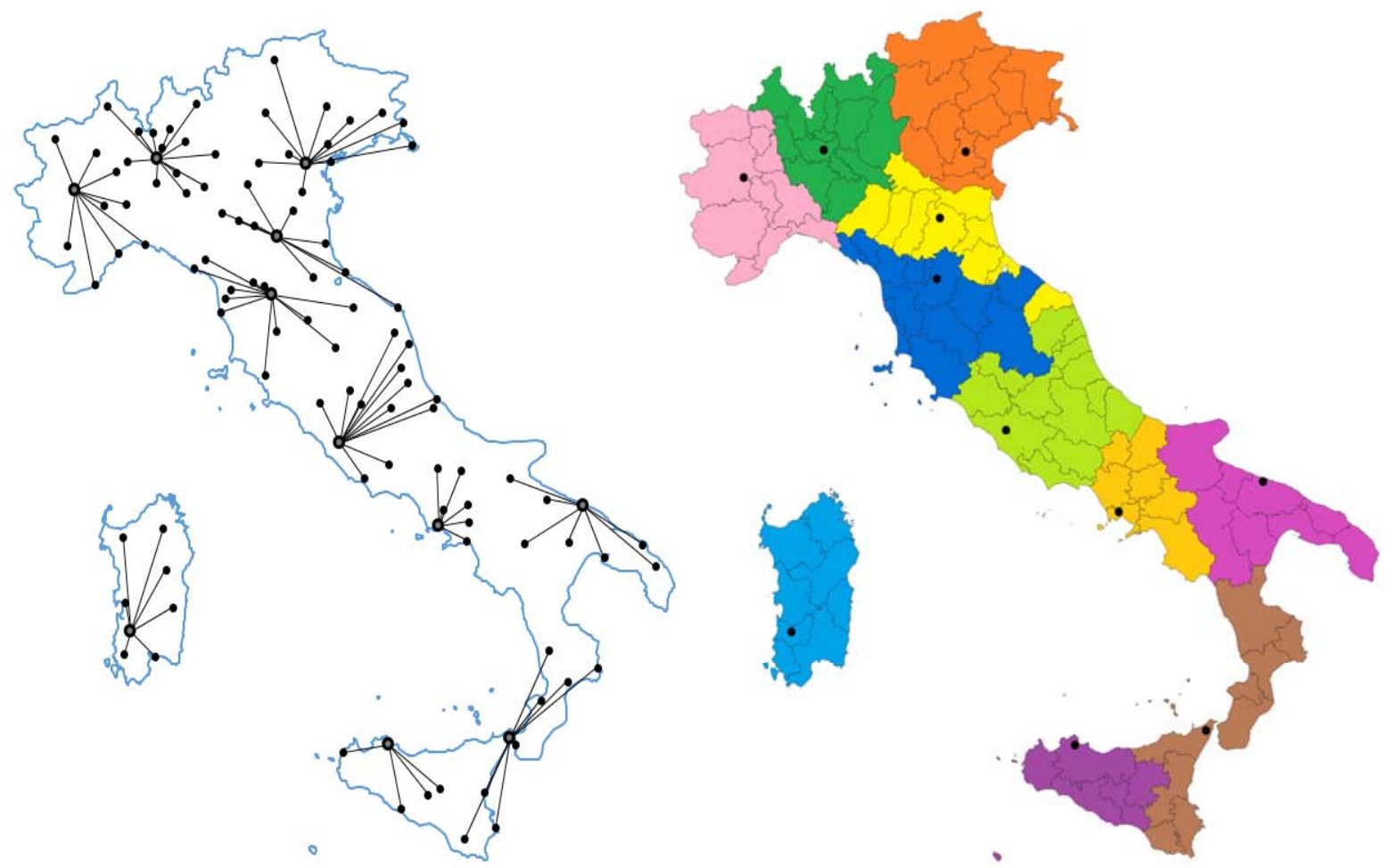

Figure 3. P-median model optimization 
To obtain a solution for uncapacitated fixed charge location model we decided to apply both construction and improvement algorithms. It will be possible to compare the solutions and choose the best possible layout with highest impact on objective function optimization. The computational complexity was shortened by programming an application in Visual Basic language to process data in Microsoft Excel. Comparable solutions of uncapacitated fixed charge location problem are presented below (Tab. 4). Since the results of both improvement algorithms are equal, presented is only one common solution. For ADD algorithm we have not achieved the improved result at all.

Table 4. Solution for uncapacitated fixed charge model obtained by various algorithms

\begin{tabular}{|c|c|c|c|c|}
\hline Algorithm & ADD & $\begin{array}{r}\text { ADD } \\
+ \text { improvement }\end{array}$ & DROP & $\begin{array}{r}\text { DROP } \\
+ \text { improvement }\end{array}$ \\
\hline Number of facilities & 12 & 12 & 13 & 13 \\
\hline Locations & $\begin{array}{r}1,19,33,43,51 \\
62,67,78,83,95 \\
96,109\end{array}$ & $\begin{array}{r}1,19,33,43,51,62 \\
67,78,83,95,96,109\end{array}$ & $\begin{array}{r}1,19,28,31,51,61 \\
67,78,83,89,95,100 \\
105\end{array}$ & $\begin{array}{l}1,19,28,32,51,61,67 \\
78,83,89,95,100,109\end{array}$ \\
\hline Avg. weighted distance [min] & 55.74 & 55.74 & 51.98 & 51.41 \\
\hline Max. distance [min] & 234.00 & 234.00 & 231.00 & 170.00 \\
\hline Fixed costs $[€]$ & 12000000 & 12000000 & 13000000 & 13000000 \\
\hline Transport costs $[€]$ & 16142150.49 & 16142150.49 & 15055828.86 & 14889227.78 \\
\hline Total Cost $[€]$ & 28142150.49 & 28142150.49 & 28055828.86 & 27889227.78 \\
\hline $\begin{array}{l}\text { Difference from best obtained } \\
\text { solution [\%] }\end{array}$ & 0.907 & 0.907 & 0.597 & 0.000 \\
\hline
\end{tabular}

We found out that the minimum costs for given input values are achieved when applying DROP algorithm with subsequent improvement algorithms. Such solution assumes locating thirteen facilities at nodes representing the covering regions of cities Torino, Milan, Verona, Venice, Florence, Ancona, Rome, Naples, Bari, Cosenza, Palermo, Catania and Medio Campidano. The establishment of high-level nodes in these locations ensures the covering of all demands of the entire Italian territory while minimizing the building and transport costs. The assignments of demand nodes to individual located facilities corresponding to the final solution as well as graphic visualizations are presented below.

Table 5. Result for individual facilities of best obtained solution for uncapacitated fixed charge model

\begin{tabular}{|c|c|c|c|c|c|}
\hline Node & $\begin{array}{c}\text { Fixed costs } \\
{[€]}\end{array}$ & $\begin{array}{l}\text { Demand weighted } \\
\text { transport costs }[€]\end{array}$ & $\begin{array}{l}\text { Average distance to } \\
\text { demand nodes } \\
{[\mathrm{km}]}\end{array}$ & $\begin{array}{c}\text { Number of assigned } \\
\text { demands }\end{array}$ & $\begin{array}{c}\text { Percentage of covered } \\
\text { demands }\end{array}$ \\
\hline 1 & 1000000 & 1459513.326 & 82.800 & 5316263 & $8.94 \%$ \\
\hline 19 & 1000000 & 1473058.985 & 62.583 & 8510587 & $14.32 \%$ \\
\hline 28 & 1000000 & 2602847.359 & 75.000 & 7753476 & $13.05 \%$ \\
\hline 32 & 1000000 & 995872.234 & 63.444 & 4316448 & $7.26 \%$ \\
\hline 51 & 1000000 & 1269776.839 & 73.583 & 4282270 & $7.21 \%$ \\
\hline 61 & 1000000 & 1607572.716 & 89.900 & 3606310 & $6.07 \%$ \\
\hline 67 & 1000000 & 886315.079 & 70.875 & 6336002 & $10.66 \%$ \\
\hline 78 & 1000000 & 809762.686 & 63.571 & 6080470 & $10.23 \%$ \\
\hline 83 & 1000000 & 1446020.613 & 73.000 & 4630602 & $7.79 \%$ \\
\hline 89 & 1000000 & 260741.663 & 59.750 & 1408083 & $2.37 \%$ \\
\hline 95 & 1000000 & 538827.916 & 71.750 & 2393438 & $4.03 \%$ \\
\hline 100 & 1000000 & 831592.951 & 65.833 & 3160433 & $5.32 \%$ \\
\hline 109 & 1000000 & 707325.413 & 89.250 & 1639362 & $2.76 \%$ \\
\hline
\end{tabular}



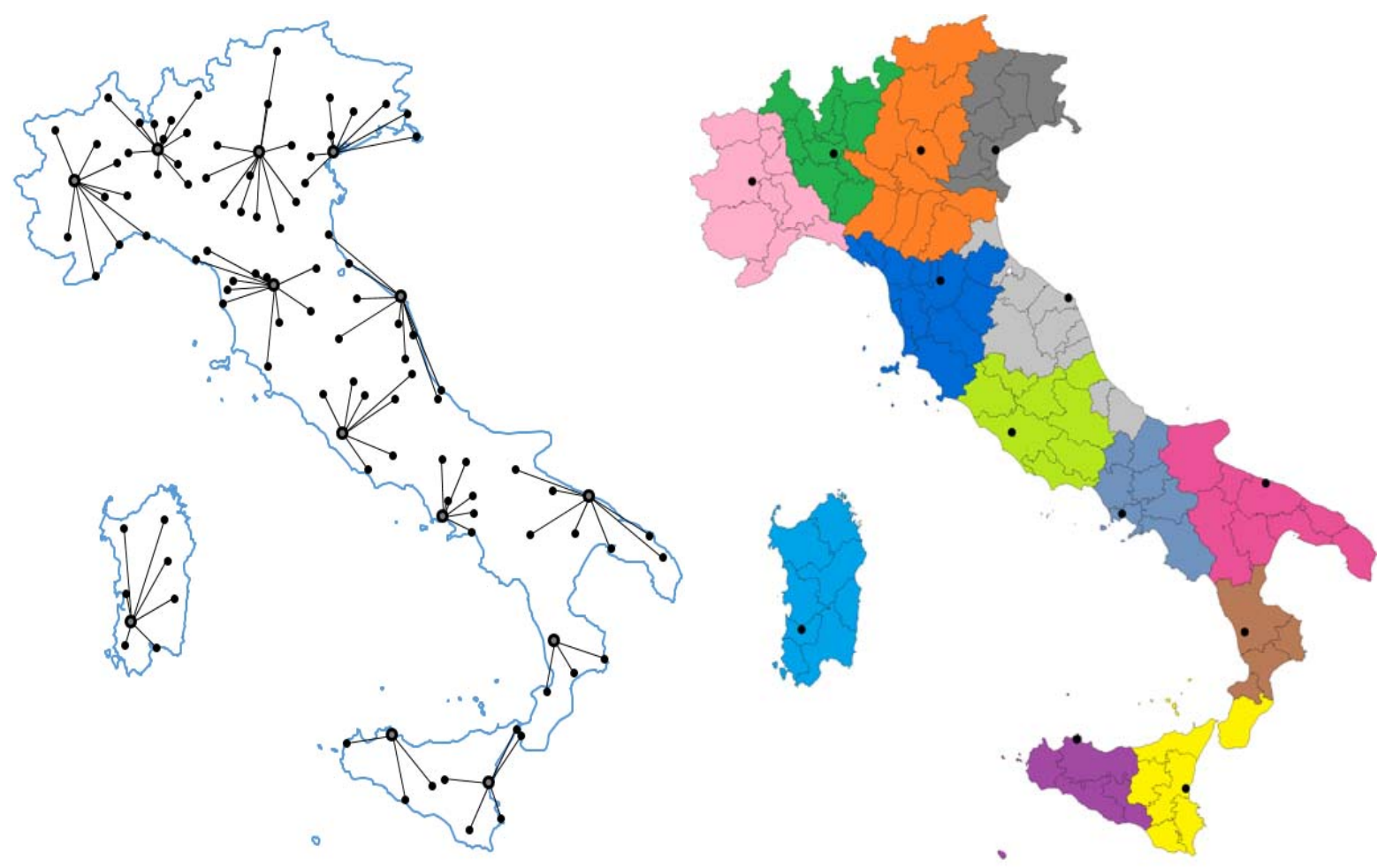

Figure 4. Uncapacitated fixed charge model optimization

\section{Conclusions}

Based on above mentioned characteristics and parameters of both models, we can observe their similarities and differences. Both models were applicable on the same network, which is represented by complete weighted graph $G=(V, H, c, w)$ to simplify the calculations. Both had the same set of nodes and edges as well as evaluation (weight) of nodes and edges. Input variables include a set of nodes with demands to be served, set of candidate nodes for facility location, the demand value of individual nodes and the distance between each pair of nodes.

The input variable of p-median location model was also the number of facilities to be located on network. Algorithms solving this model were looking for mathematically optimal solution for given number of facilities and finish after finding it. This model did not count with the cost of building up the facilities; it tried to find the solution with minimal transport costs.

The uncapacitated fixed charge location problem did not have a specified number of facilities on input, which increased the variability of solution. The input variables included costs per distance unit per demand unit, which were relatively difficult to determine. Also the costs of building up facilities may differ in each node. However, in addition to mathematically optimal solution, this model brings significant degree of economical optimality compared to the p-median location model.

Such optimality is required when strategic decisions are made, similar to locating the postal processing and distribution centers. Therefore, for the solution of decision problem addressed in this article we will use both models the uncapacitated fixed charge location model and p-median location model.

Since the current layout of middle-level covering regions is obsolete, it would be necessary to deal with the issue of changing the covering area and reducing their number. After such optimization the presented model can bring even better results. Application of p-median and uncapacitated fixed charge facility location model on selected infrastructure resulted in finding the location of eleven or thirteen facilities.

The obtained sub-optimal results and used calculations can serve as a cornerstone for further search of optimal solution by allocation models in the field of postal networks. 


\section{Acknowledgements}

This contribution was undertaken as part of the research project 1/0721/15 VEGA Research on the impact of postal services and telecommunication convergence on regulatory approaches in the postal sector.

\section{References}

1. Ahuja, R.K., Magnanti, T.L. and Orlin, J.B. (1993) Network Flows: Theory, Algorithms, and Applications. New Jersey: Prentice Hall. 846 p.

2. Daskin, M.S. (2010) Service Science. Hoboken: John Wiley \& Sons, 576 p.

3. Droździel, P., Komsta, H. and Krzywonos, L. (2013) Repair costs and the intensity of vehicle use, In: Transport Problems, Volume 8, Issue 3, 2013, Pages 131-138.

4. Madleňák, R., Madleňáková, L. and Štefunko, J. (2015) The Variant Approach to the Optimization of the Postal Transportation Network in the Conditions of the Slovak Republic, Transport and Telecommunication. Volume 16, Issue 3, Pages 237-245, ISSN (Online) 1407-6179, DOI: 10.1515/ttj-2015-0022.

5. Hakimi, S.L. (1964) Optimum Location of Switching Centers and the Absolute Centers and Medians of a Graph. In: Operations Research. 1964. Vol. 12, P. $450-459$.

6. Daskin, M.S. (2013) Network and discrete location: Models, algorithms and applications. Hoboken: John Wiley \& Sons, 2013. 518 p.

7. Cornuejols, G., Nemhauser, G.L. and Wolsey, L.A. (1990) The Uncapacitated Facility Location Problem. Discrete Location Theory. 1990. Chapter 3. New York: Wiley, Chapter 3, P. 119-171.

8. Madleňák, R. (2006) Alternatívne možnosti konštrukcie poštovej prepravnej siete. In: Proceedings of International Conference "Perner's contacts". Pardubice: Univerzita Pardubice 2006, Vol. 1, No. 2. P 48-52. [In Slovak: Alternative possibilities for postal network construction]

9. Madleňák, R. and Zeman, D. (2009) Construction of postal transportation network in conditions of Slovak republic. In: Proceedings of International Conference "Postpoint 2009". Žilina: Žilinská univerzita, 2009.

10. Madleňáková, L. (2014) Layers Modeling of Postal System, In: Diagnostic, controlling and logistics of enterprises : international scientific conference : Žilina, 2014, ISBN 978-80-554-0856-9. s. 224230. In Slovak: Modelovanie vrstiev poštového system.

11. Global and regional estimates. Universal Postal Union (2015) Available at: $\mathrm{http}: / /$ pls.upu.int/pls/ap/ssp_report.main? p_language=AN\&p_choice=BROWSE

12. Čorejová, T., Achimský, K., Fitzová, M. and Kajánek, B. (1995) Projektovanie sietí v pošte I. Žilina: Edičné stredisko VŠDS. 1995. 147 p. [In Slovak: Designing networks in postal industry I.]

13. Madleňák R., Madleňáková L. and Pavličko M. (2014) Postal Transportation Network: Design and Construction. Žilina. Žilinská Univerzita, 2014, p. 236.

14. Vaculík, J., Kolarovszki, P. and Tengler, J. (2012) Results of automatic identification of transport units in postal environment, Transport and Telecommunication. Volume 13, Issue 1, Pages 75-87, ISSN (Online) 1407-6179, ISSN (Print) 1407-6160, DOI: 10.2478/v10244-012-0007-7

15. Hrudkay, K. (2012) Functional requirements for information system of intermodal transport terminals, In: Doprava a spoje: FPEDAS, University of Zilina. - ISSN 1336-7676. 2/2012. pp. 168177.

16. Garey, M.R. and Johnson, D.S. (1979) Computers and Intractability: A Guide to the Theory of NPCompleteness. New York, USA: W. H. Freeman and Co. 1979.

17. Dresner, Z. and Hamacher, H.W. (2002) Facility Location; Applications and theory. Berlin, Germany: Springer. 2002. p. 81-107.

18. Maranzana, F.E. (1968) On the Location of Supply Points to Minimize Transport Costs. In: Journal of the Operational Research Society, 15. 1968. p.261-270. doi:10.1057/jors. 1964.47

19. Teitz, M.B. and Bart, P. (1968) Heuristic methods for estimating generalized vertex median of a weighted graph. In: Operations research, 16. Maryland, USA: INFORMS. 1968. 955-961. http://dx.doi.org/10.1287/opre.16.5.955 